\section{8d CHALLENGES IN DIAGNOSIS AND PREVENTION OF OCCUPATIONAL RESPIRATORY DISEASES}

JH Rantanen. University of Helsinki, Department of Public Health/Occupational Health, Helsinki, Finland

\subsection{6/oemed-2018-ICOHabstracts.654}

Occupational respiratory diseases (ORDs) constitute one of the most prevalent groups of occupational diseases (ODs) with a multitude of diagnoses (pneumoconioses, other fibroses, infectious diseases, airway diseases such as asthma and COPD, other hypersensitivities and irritations, and most importantly, cancers. In addition to acute or subacute outcomes, ORDs may result from cumulative exposures during years or decades and in cancers latency periods of up to 50 years may occur. They often have a progressive course with severely disabling or fatal outcome. Their diagnosis is highly demanding and need multiprofessional, multidisciplinary teamwork, such as occupational medicine, pulmonology, occupational hygiene, clinical physiology, and also well-established clinical facilities with advanced laboratory and imaging resources.

The diagnostic process follows the generic logic of diagnosis of ODs, including early monitoring of exposures (workplace surveillance), observation of subclinical findings of groups at risk, early notification of symptoms (workers' health surveillance), careful examination of work and exposure history (occupational hygiene and anamnesis), clinical investigation (physical, clinical studies, laboratory analyses, imaging, possible functional testing and follow-up at work and possible provocation tests, e.g. in asthma). In cases of cancers with long latencies, the health surveillance needs to be extended upon the retirement age and beyond.

In good occupational health practice, the process does not end with the diagnosis. In addition to proper treatment, a thorough statement, based on acquired evidence of the diagnosed outcome is needed for legal and insurance purposes. Rehabilitation measures may be needed. The notification to the authorities and OD registries will be made. In many countries, the examination of the workplace and feedback for prevention of further cases is obligatory. Severe and fatal cases of ODs lead e.g. in Finland to police investigation.

For adequate preventive measures, structural, primary, secondary and tertiary prevention are needed and the earliest possible identification of disease is emphasised.

\section{8e CHALLENGES IN DIAGNOSIS AND PREVENTION OF OCCUPATIONAL SKIN DISEASES}

SM John. Dept. Dermatology, Environmental Medicine, Health Theory, University of Osnabrueck, Germany

\subsection{6/oemed-2018-ICOHabstracts.655}

Work-related skin diseases (WRSD) are at the top of all notified occupational diseases with a share of more than $40 \%$ in some European countries. For example, currently, in Germany, about $30 \%$ of annual notifications fall on irritant or allergic contact dermatitis, another $10 \%$ on certain forms of occupational nonmelanoma skin cancer by solar UV radiation exposure at the workplace. For WR contact dermatitis (ILO-list: 2.2.1 and 2.2.2), it can be stated that targeted prevention strategies have shown to be highly effective in notified cases, however, the reach out to affected workers is still limited in many countries due to underreporting. Prevention measures include improved workers' education, specific barrier-recovery oriented skin care methods, better use of protective equipment, selection of safer products, and early medical intervention. Recently, required minimum standards for WRSD prevention, postulating the above mentioned concepts in an interlocking preventive system, have recently been published in Europe. Regarding WR skin cancer in outdoor workers a similar efficacy of organisational measures, workers' education, and suitable protective equipment based prevention measures is to be expected; again, such preventive measures would be similarly easy and comparatively cheap to implement. However, in occupational skin cancer, even more so than with WR contact dermatitis, preventive measures are neglected. Furthermore, occupational skin cancer by solar UV radiation exposure at the workplace is not yet recognised as an occupational disease in many countries, contributing amongst other factors largely to the gross underreporting, and, thus, lack of preventive intervention.

UV radiation has been clearly identified as carcinogenic to humans by the International Agency for Research on Cancer (IARC), even fulfilling group I definitions for complete carcinogens, like eg Plutonium and Arsenic. The more it is astounding, that there is yet no clear work protection regulation for outdoor workers on the level of the EU; so far work protection does only comprise artificial UVR sources. The ILO list of occupational diseases includes multiple reference to occupational cancers and occupational diseases by physical radiation. The ILO Guidance Notes on Diagnostic and Exposure Criteria for Occupational Diseases will describe this specific occupational risk in outdoor workers. This will be an important step to meet the yet unmet challenge of nonmelanoma skin cancer to occupational medicine, considering that it is by far the most frequent and by incidence and prevalence fastest growing occupational malignancy.

\section{$1658 f$ DIAGNOSIS, PREVENTION AND COMPENSATION OF OCCUPATIONAL DISEASES IN THE RUSSIAN FEDERATION}

I Bukhtiyarov. FSBSI 'Izmerov Research Institute of Occupational Health', Moscow, Russia

\subsection{6/oemed-2018-ICOHabstracts.656}

In the countries of EU simultaneously act several lists of occupational diseases (OD) (opened, closed, closed regulated). National list of OD in the Russian Federation (RF) is opened type. In common RF OD list is harmonised with ILO OD list (revised 2010) with some exceptions. For example, National OD list does not recognise work related diseases.

The dynamics of the number of cases of OD in the RF in 2011-2015 and OD level (per 100 thousand people) and their trends for 2016-2030 were studied compared to the level of OD in the EU countries-27. In 2011 the number of new cases of OD was 8923 (the population were 142.9 million people); in 2015 г. the number of detected cases of occupational diseases was 7410 (the population were 146.3 million people). The level of OD was decreased from 6.24 (2011) up to 5.06 (2015) per 100 thousand people. The analysis of OD level shows that the number of detected cases of OD for the first time in the RF was significant (7-8 times) lower than in UN countries-27-40.07 per 100 thousand population (2014). 
Structure of OD in RF shows than maximal part of OD are diseases caused by physical agents (48.85\%), hearing impairment caused by noise and disease caused by vibration including. The another main ODs were: ODs caused by chemical agents as well as occupational respiratory and occupational skin diseases. There are absent post traumatic stress disorders and dramatic low level of occupational cancer. Over 20022014 , total of 498 cases of occupational cancer was registered, that is less than $0,3 \%$ of minimal expected number of cases.

This is connected with peculiarities of OD registration system and underestimation real level of OD. All this justifies the need of occupational diseases diagnosis, prevention and compensation system improving in the RF.

\section{$1658 \mathrm{~g}$ DIAGNOSIS, PREVENTION AND COMPENSATION OF ODS IN CHINA}

Z Min. Chinese Academy of Medical Sciences (CAMS)/Peking Union Medical College (PUMC)

\subsection{6/oemed-2018-ICOHabstracts.657}

Introduction Occupational health is fundamental for the Sustainable Development Goals(SDGs) across the world, China has launched a new run of Healthy China 2030 Plan in 2017 , it is of great impact to occupational diseases(OD) prevention and Control in China.

Methods To analyse the situation of OD prevention and control in China, in the context of dynamic system with policy development and organisational facilitating.

Results First, There have been strong policy advocacy of DO prevention and control in China recently, including National Plan on Prevention and Control of Occupational Diseases (2016-2020), National occupational health standards and implementation, and National major occupational diseases sentinel monitoring programme, et al. Second, System of Policymaking and regulation enforcement is optimising, among departmental organisations, ODs reporting and notification system, as well as national occupational health standard committee. Third, There are strong points and weakness in policies relate to OD diagnosis, prevention and compensation in China, particularly analysis on Law of the People's Republic of China on Prevention and Control of Occupational Diseases, Regulation of the People's Republic of China on Work-Related Injury Insurances.

Discussion Opportunities and challenges of diagnosis, prevention and compensation of ODs in China are unprecedented, harmonised management system of occupational health at varied level is the key to purchase the goal of decent work, health and well-being and sustainable development in China.

\section{$1658 \mathrm{~h}$ THE STATUS OF SURVEILLANCE FOR OCCUPATIONAL DISEASES IN THE USA}

Linda Forst. University of Illinois at Chicago School of Public Health, Illinois, US

10.1136/oemed-2018-ICOHabstracts.658
The goal of occupational surveillance is to document and characterise occupational hazards or adverse health effects; to monitor trends over time; to identify emerging problems; to generate hypotheses for research; and to evaluate the effectiveness of interventions. The U.S. Bureau of Labour Statistics collects and maintains data on occupational injuries, illnesses and fatalities and makes it available to the public. The gaps in the US national system are supplemented by a variety of other resources. This presentation will describe the US national system, the challenges to obtaining complete and accurate information, other sources of data and linkage methods that can fill the gaps, and recommendations for a more comprehensive system. Occupational surveillance challenges are universal and the potential ways to overcome them can be adapted according to local needs.

\section{SINCE WORK IS NEVER DONE: A PLEA FOR OSH VIGILANCE}

Annet Lenderink. Netherlands Centre for Occupational Diseases, Coronel Institute on Work and Health, AMC/University of Amsterdam, Netherlands

\subsection{6/oemed-2018-ICOHabstracts.659}

Continuous updating of criteria documents and guidelines is helpful in the improvement of recognising and reporting of occupational and work-related diseases. But these documents focus on known exposure-disease combinations. Meanwhile work, work settings and work procedures are continuously changing which can lead to new occupational health risks. In those cases the occupational physician who has to establish an aetiological diagnosis can usually not rely on existing criteria. $\mathrm{He}$ needs to go from deductive reasoning - going from the 'general' knowledge to the 'specific' case - to a more inductive reasoning in which he gets from the observation of a specific case to a more general hypothesis about the potential causal relation with work exposure. This searching for the unknowns in work and health is a process with lots of uncertainties and few underpinning research.

Other scientific fields like pharmacovigilance may help us out. Pharmacovigilance is the approach to detect new and emerging adverse effects of drugs after their release in the market. This type of post marketing surveillance is characterised by gathering signals, strengthening signals, validating signals and acting on signals can be copied and used to detect new and emerging health risks in work situations. This could be addressed as occupational safety and health (OSH) vigilance. Within the MODERNET network, several methods and approaches of $\mathrm{OSH}$ vigilance are being explored and implemented, such as datamining in existing databases (e.g. French RNV3P), investigating reported cases in sentinel surveillance schemes (e.g. Norwegian RAS, SENSOR-Pesticides USA), investigating unusual events (e.g. French GAST, and HHE-program USA) and reporting and assessing new and emerging risks (e.g. SIGNAAL, OccWatch, and THOR-extra). International collaboration is imperative to detect rare signals earlier, to strengthen and validate signals easier, to have a wider variety of expertise available, to use scarce resources more effectively, and to increase dissemination to relevant stakeholders. 